\title{
Educação na pandemia: jogos e brincadeiras on-line com crianças em
}

\section{tratamento de saúde}

\author{
Pandemic education: online games and games with children in health care \\ Educación en la pandemia: juegos y bromas en línea con los niños en el cuidado de la salud
}

Recebido: 14/10/2021 | Revisado: 21/10/2021 | Aceito: 23/10/2021 | Publicado: 25/10/2021

\author{
Joelma Fátima Castro \\ ORCID: https://orcid.org/0000-0001-8948-7406 \\ Universidade Estadual de Maringá, Brasil \\ E-mail: castrojoelmaf@gmail.com \\ Silvia Mara da Silva \\ ORCID: https://orcid.org/0000-0002-1019-6065 \\ Universidade Estadual de Maringá, Brasil \\ E-mail:pg402146@uem.br \\ Eliandra Cardoso dos Santos Vendrame \\ ORCID: https://orcid.org/0000-0002-6212-0847 \\ Universidade Estadual de Maringá, Brasil \\ E-mail: eliandravendrame@gmail.com \\ Ercília Maria Angeli Teixeira de Paula \\ ORCID: https://orcid.org/0000-0002-8619-7558 \\ Universidade Estadual de Maringá, Brasil \\ E-mail: erciliaangeli@yahoo.com.br
}

\begin{abstract}
Resumo
No ano de 2020, o isolamento social resultante da pandemia COVID-19 trouxe desafios para a efetivação do processo ensino-aprendizagem. Frente a esta nova e inesperada realidade surgiu a problemática "O brincar pode ser uma estratégia da Educação Social em Saúde com criança com câncer na pandemia?”. Em face disto, o objetivo deste artigo é demonstrar de que modo o brincar pode ser utilizado como estratégia na prática da Educação Social em Saúde de crianças com câncer no Ensino Remoto de Emergência (ERT). A metodologia do trabalho foi estudo de caso, com abordagem qualitativa, por meio da realização de onze encontros utilizando a ferramenta Google Meet. Foi desenvolvida uma revisão de literatura sobre práticas lúdico-pedagógicas em ambientes virtuais e análise das atividades realizadas. O referencial teórico foi fundamentado em Paulo Freire (1967, 1989, 2002), Buber, Schütz (1993), Schütz e Lckmann e Vigotsky (1988). Os resultados apontaram que as ações em ambiente on-line promoveram a construção de conhecimentos com as crianças e contribuem para a formação inicial de professores por meio do projeto de extensão. As brincadeiras asseguram o acesso à educação durante o período de pandemia.
\end{abstract}

Palavras-chave: Câncer; Brincadeira; Ensino remoto.

\begin{abstract}
In 2020, social isolation resulting from the COVID-19 pandemic posed challenges for the implementation of the teaching-learning process. Faced with this new and unexpected reality, a problem arose: "Can play be a strategy of Social Education in Health with children with cancer in the pandemic?". Therefore, the objective of this article is to demonstrate how playing can be used as a strategy in the practice of Social Education in Health for children with cancer in Emergency Remote Education (ERT). The methodology of the study was case, with a qualitative approach, through eleven meetings using the Google Meet tool. A literature review was developed on ludic-pedagogical practices in virtual environments and analysis of the activities performed. The theoretical framework was based on Paulo Freire (1967, 1989, 2002), Buber and Schütz (1993), Schütz, Lckmann, and Vygotsky (1988). The results showed that the actions in online environment promoted the construction of knowledge with children and contribute to the initial training of teachers through the extension project. Play ensures access to education during the pandemic period.
\end{abstract}

Keywords: Cancer; Playing; Remote teaching.

\section{Resumen}

En el año 2020, el aislamiento social, resultante de la pandemia COVID-19, trajo desafíos para la efectividad del proceso de enseñanza-aprendizaje. Frente a esa nueva e inesperada realidad, surgió la problemática: “¿El jugar puede ser una estrategia de la Educación Social en Salud con niño con cáncer en la pandemia?”. En base de eso, el objetivo de este artículo es demostrar de qué modo el juego puede ser utilizado como estrategia en la práctica de la Educación Social en Salud de niños con cáncer en la Enseñanza Remota de Emergencia (ERT). La metodología del trabajo fue 
investigación de caso, con enfoque cualitativo, por medio de la realización de once encuentros utilizando la herramienta Google Meet. Se desarrolló una revisión de literatura sobre prácticas lúdico-pedagógicas en ambientes virtuales y análisis de las actividades realizadas. El referencial teórico fue fundamentado en Paulo Freire (1967, 1989, 2002), Buber y Schütz (1993), Schütz, Lckmann y Vygotsky (1988). Los resultados evidenciaron que las acciones en ambiente online promovieron la construcción de conocimientos con los niños y contribuyen para la formación inicial de profesores por medio del proyecto de extensión. Los juegos aseguran el acceso a la educación durante el período de pandemia.

Palabras clave: Cáncer; Broma; Enseñanza remota.

\section{Introdução}

O brincar sempre foi alvo de discussões entre pesquisadores e educadores, ao pensar como a brincadeira pode contribuir no desenvolvimento da criança, Navarro (2009, p. 2124) descreve que "é necessário, é importante ser criança, ter tempo para brincar, socializar, olhar para o mundo com o olhar da criança sem tantas pressões e responsabilidades". Diante dessa fala, sabemos que a brincadeira está presente no cotidiano da criança, tais como pic-esconde, a amarelinha, jogos, dentre outras brincadeiras realizadas em espaços escolares e não escolares.

Uma das preocupações que surgem diante da pandemia é como as crianças em tratamento de câncer que recebem atendimentos educacional domiciliar e hospitalar também vivenciaram e vivenciam a interrupção das atividades educacionais presenciais, ocasionando um impacto em seu bem-estar e de seus familiares. Considera-se que o atendimento a estas crianças não apenas proporciona o aprendizado, mas também possibilita que elas vivenciem o brincar, estabeleçam relações e se desenvolvam integralmente.

Antes da pandemia COVID-19, a Educação Social em Saúde, em seu cotidiano de atendimento educacional para crianças com câncer, privilegiou em sua prática pedagógica o diálogo como conceito principal, valorizando o contexto sóciohistórico dessas crianças, tendo nas relações humanas o ponto de partida para a ação educacional. Abrigada na teoria de Paulo Freire, assume a educação como uma prática social na qual a formação humana é pautada no diálogo.

No período de pandemia, a continuidade do atendimento educacional para crianças em tratamento de câncer no campo da Educação Social em Saúde visou contribuir para promover a organização do cotidiano dessas crianças em seus lares, respondendo às necessidades lúdicas apresentadas por estas, agora isoladas em suas casas com seus familiares.

Tendo conhecimento da realidade dessas crianças já sedimentado em práticas educativas antes da pandemia, buscouse a construção de uma estratégia educacional, optando-se pelo brincar, sendo que os educadores se colocaram "como pessoa, agente, respeitando a individualidade, das crianças, seus valores e suas expectativas. Como autenticidade, verdade e coerência" (Freire, 1989, p. 13).

Diante dessa inesperada realidade, surgiu a problemática a ser investigada neste estudo, que parte da seguinte pergunta: "O brincar pode ser uma estratégia da Educação Social em Saúde com criança com câncer na pandemia?"

Partindo desse questionamento, temos como objetivo do nosso artigo demonstrar como o brincar pode ser utilizado como estratégia na prática as Educação Social em Saúde de crianças com câncer no contexto do Ensino Remoto de Emergências (ERT).

Para a concretização deste estudo, foi adotada uma abordagem qualitativa, por meio do estudo de caso, visando à compreensão do problema a ser pesquisado. Conforme Terence e Escrivão Filho (2006), a pesquisa qualitativa é utilizada para interpretar fenômenos, na qual o pesquisador busca aprofundar-se no estudo de um tema. De acordo com Vergara (2005), a pesquisa qualitativa é uma alternativa para explorar o objeto de estudo e delimitar o campo de estudo.

Quanto à fundamentação teórica, foi desenvolvida uma pesquisa bibliográfica para aprofundar os conceitos e pressupostos teóricos que nortearam essa investigação. Segundo Gil (2007, p. 64), a "pesquisa bibliográfica é desenvolvida a partir de material já elaborado, constituído principalmente de livros e artigos científicos”. 
Pensando em nosso objetivo, inicialmente apresentaremos como o recurso midiático da plataforma Google Meet como ferramenta estratégica foi utilizado para a atuação prática das ações do projeto de extensão com crianças em tratamento de saúde, de acordo com a definição de Ensino Remoto de Emergência (ERT). Posteriormente, discutiremos como foram as experiencias por meio do Meet com as crianças e quais as contribuições alcançadas ao realizar as atividades de forma remota com as crianças em tratamento de saúde.

\section{Metodologia}

Este trabalho caracteriza-se como uma pesquisa qualitativa, estudo de caso. Qualitativa pois conforme Bogdan e Biklen (1994, p. 50) descrevem "Os investigadores que fazem uso deste tipo de abordagem estão interessados no modo como diferentes pessoas dão sentido às suas vidas" e estudo de caso por permitir o uso de diversas técnicas na investigação e ao mesmo tempo preservar as características reais segundo Yin (2001).

$\mathrm{O}$ ato de conduzir (educere) ou educar, no âmbito educacional, ganha novas considerações no contexto da pandemia, pois a experiência presencial foi substituída pela interação virtual entre crianças, adolescentes e professores.

Em decorrência do estado de emergência na saúde causada pelo novo Coronavírus (COVID-19), notificado inicialmente em 31 de dezembro de 2019 na cidade de Wuhan-China e devido à rápida disseminação comunitária em todos os continentes, bem como o grau de letalidade entre os contaminados, a OMS (Organização Mundial de Saúde) declarou que estamos vivenciando uma pandemia. Para contê-la, o órgão recomenda três ações básicas: tratamento dos casos identificados, testes em larga escala da população e distanciamento social. No Brasil, em portaria emitida em 03 de fevereiro, o Ministério da Saúde declarou emergência nacional em saúde. Por conseguinte, as autoridades adotaram medidas a partir das quais estados e municípios vêm editando decretos e outros instrumentos normativos legais para o enfrentamento da pandemia. Dentre estes, a suspensão das atividades escolares presenciais, de modo a conter a doença que se tornou uma ameaça crescente e gerou impactos na vida dos seres humanos, incluindo a educação (Almarzooq, Lopes \& Kochar, 2020).

Ao considerar o estado atual da educação no Brasil, verifica-se que o ensino didático presencial necessitou ser adaptado para o Ensino Remoto de Emergência (ERT) em razão do distanciamento social, que foi a medida adotada para amenizar a disseminação do COVID-19. Assim, o mundo da vida dessas pessoas, constituído de suas rotinas diárias e interações (Schutz, 1993), tanto de professores quanto alunos, foi afetado por essa nova realidade.

Os estudos teóricos que tratamos neste texto partem da prática desenvolvida em um projeto de extensão de Educação Social em Saúde, pautados na perspectiva da educação libertadora do educador Paulo Freire, cuja premissa é a dialogicidade entre sujeitos, procurando ouvir crianças e adolescentes, assim compreendendo seus desejos, suas angústias, suas alegrias e aflições e buscando de forma coletiva elucidar seus problemas.

Nesse projeto da Educação Social em Saúde, um referencial teórico que completa as referências da Educação Social são os princípios de Gazzinelli, Gazzinelli, Reis \& Penna (2005, p. 204), os quais consideram relevantes os trabalhos de promoção da autonomia das pessoas: "Ressalta-se a formação de uma rede de solidariedade entre educadores e educados, na qual se busca o compartilhamento e o desenvolvimento de potencialidades na tentativa de ultrapassar limites e dificuldades, outorgando autonomia dos sujeitos envolvidos".

Assim, pela perspectiva das ações de educação Social em Saúde, os sujeitos são considerados pessoas com histórias de vida, que expressam desejos, sentimentos e possuem aptidões para reinventarem modos de vida e formas de organização social. A Educação Social em Saúde concebe suas práticas educativas como ações de liberdade e empoderamento, assim como já afirma Freire (1967).

Para a consecução das estratégias metodológicas, foi utilizada a ferramenta Google Meet, que é um recurso para fazer chamadas de videoconferência. Essa ferramenta permitiu que onze encontros remotos fossem realizados em tempo real, nos 
quais ocorreu a interação com as crianças que participaram do projeto de extensão por meio de brincadeiras e ações literárias mediante os princípios pedagógicos da Educação Social em Saúde.

No ano de 2020, devido à pandemia decorrente do COVID-19, em razão das medidas de isolamento social, novos direcionamentos foram estabelecidos para realizar encontros com grupo de crianças em tratamento de câncer em um projeto de extensão.

O projeto de extensão foi iniciado em 2015 em uma universidade pública no interior do Paraná. É coordenado por uma docente do curso de Pedagogia e conta com estudantes de diferentes cursos da graduação: Pedagogia, Educação Física e Artes Cênicas. Também conta com estudantes da pós-graduação em educação desta mesma universidade.

O projeto atendia inicialmente crianças que realizavam tratamento no Hemocentro do Hospital Universitário da cidade, tendo como objetivo a realização de atividades culturais, lúdicas e educacionais com as crianças em tratamento de saúde, sendo que as atividades haviam sido encerradas por motivos de reformas de infraestruturas. Assim, no ano de 2018 começou a atender crianças com câncer na ONG da cidade. Com a pandemia, foram necessários alguns ajustes nas práticas lúdicas e educativas realizadas com as crianças.

Os onze encontros semanais ocorreram por meio de chamadas de videoconferência Google Meet, entre os meses de agosto a novembro de 2020, com crianças que já participavam do projeto. Em um primeiro momento, dialogamos com os pais ou responsáveis e com as crianças e adolescentes sobre quais eram os objetivos de continuarmos realizando as atividades mesmo que de forma remota, posteriormente falamos sobre como seriam realizados os encontros.

Explicamos aos pais que a participação do seu filho (a) seria totalmente voluntária, caso não quisesse participar em algum momento, poderia se recusar. Falamos também sobre os benefícios, dentre eles: a criança e o adolescente poderem dialogar e manter contato com seus pares nesse momento de isolamento. Enfatizamos com as crianças e adolescentes que sua participação só poderia ocorrer a partir da aceitação deles e dos pais e ou responsáveis.

Diante da pandemia na qual o Brasil se encontra e pensando no bem-estar de todos os envolvidos, o convite para participar do projeto e a autorização foram realizados via plataforma Google Meet. Perguntou-se primeiramente às crianças e aos adolescentes se gostariam de participar dos encontros, concomitantemente perguntamos aos pais ou responsáveis de cada participante se autorizariam que seus filhos participassem das ações realizadas pelo projeto de extensão.

As crianças ficaram bem empolgadas em participarem das atividades, pois muitas não estavam tendo nenhum contato com outras crianças, elas gostavam de se ver na tela do computador e conversar com outras crianças, bem como os familiares. Os pais foram bem receptivos com a proposta da realização das atividades de forma on-line, pois a questão do isolamento era algo que os preocupava, uma vez que sentiam a necessidade de seus filhos terem contato e poderem brincar com outras crianças.

A ferramenta Google Meet foi utilizada uma vez por semana com duração de uma hora, porém em alguns encontros esse horário se excedeu, pois, as crianças queriam ficar mais tempo nas rodas de conversa e brincadeiras. Durante os diálogos, elas contaram sobre suas vivências na pandemia, as dificuldades com o grande número de tarefas da escola e a saudade das professoras, amigos e do projeto presencial.

A partir da escolha do Meet, buscou-se uma breve formação entre os próprios educadores/ pesquisadores, que desenvolveram um processo de tentativas e descobertas, incluindo sobre a utilização da ferramenta. Apesar dos esforços para que as aulas chegassem às crianças participantes, percebeu-se que não eram todos que possuíam acesso aos meios digitais.

Nas primeiras ações, procuramos orientar as crianças e os pais sobre a utilização do Meet, do mesmo modo que para nós era tudo novo, para eles também. As crianças adoravam se ver na tela e aprenderam também como utilizar o chat, escreviam seus nomes, escreviam o nome dos colegas. 
Durante os encontros, as crianças e adolescentes participaram ativamente das brincadeiras propostas, queriam mostrar seu universo aos demais participantes, mostrando seus brinquedos prediletos, seus bichinhos de estimação (gato, cachorro, galinha, coelho, tartaruga), além dos desenhos de heróis, de princesas, da escola que eles produziam e traziam para nos apresentar.

Nos encontros foram propostas as seguintes brincadeiras: careca-cabeludo, morto-vivo, elefantinho colorido, advinha, histórias inventadas com objetos, hora do desenho, qual a profissão. Além dessas atividades, contamos algumas histórias, como “A girafa sem sono" (2015), da autora Liliana Iacocca, "Os direitos das crianças" (2014), de Ruth Rocha, "Ser diferente é legal" (2018), escrito por Cida Bezerra, dentre outras.

É preciso ressaltar que as escolhas pelas brincadeiras não eram pré-determinadas, pois sempre buscávamos respeitar e ouvir cada participante. Dessa forma, algumas brincadeiras eram inventadas durante o encontro com o apoio de cada participante e comum acordo de todos, assim valorizando a vontade e o conhecimento de cada integrante e contribuindo para o desenvolvimento do projeto. Os autores descrevem a importância da relação entre a criança e o pesquisador: "O processo de pesquisar com crianças possibilita uma mediação pela qual os sujeitos imersos (crianças e pesquisador) compartilham novos conhecimentos, pois há coisas que ambos conhecem e que ambos desconhecem e que precisam ser mediadas pelo processo de pesquisa". (Rodrigues, Borges \& Silva, 2014, p. 282)

Partindo dessa troca de conhecimentos, buscamos diversificar as brincadeiras, pois acreditamos que o brincar é essencial para o desenvolvimento da criança e do adolescente, uma vez que por meio do faz-de-conta, de jogos e brincadeiras, o indivíduo se apropria de culturas geracionais, tradições e intensifica suas relações.

Em um dos encontros, pedimos que cada participante nos falasse qual era o livro que mais gostava e qual era a história predileta no livro. Uma das crianças apresentou o livro: "Ser diferente é legal", após nos contarmos sobre o livro, perguntamos: O que é ser diferente?

Alguns participantes ficaram em silêncio, outros quiseram responder: "Diferente, não somos todos iguais no mundo, porque tem gente que é marrom, tem gente que é branca, tem gente que é negra e tem gente que é bege" (DIÁRIO DE CAMPO, dezessete de agosto de 2020). Após algumas crianças responderem, continuamos conversando e explorando sobre as especificidades de cada indivíduo, por exemplo, que temos características diferentes, mas todos devem ser respeitados.

Em outros momentos, a brincadeira se tratava de uma criança desenhar algo sobre um tema escolhido, enquanto as demais precisariam adivinhar o que ela estava desenhando. Durante a brincadeira, as crianças relacionavam os desenhos com sua realidade, falando, por exemplo, sobre o emprego dos pais, a escola, os amigos, a saudade de poderem brincar na rua. Essas relações evidenciam a importância do desenho e da conversa como forma da criança se expressar, segundo:

Nesse contexto, o desenho e a oralidade são compreendidos como reveladores de concepções e olhares das crianças em relação a seu contexto social, histórico e cultural. Diante disto, convém afirmar que os desenhos infantis articulados à oralidade são formas privilegiadas de expressão da criança (Mafra, 2015, p. 114)

Assim, por meio das brincadeiras realizadas em cada encontro, foi possível conhecer e compreender a construção social e da realidade dessas crianças durante o momento de pandemia, em que se encontram isoladas em suas casas, distantes da escola, dos colegas e dos professores. Além disso, possibilitaram a garantia das crianças e dos adolescentes brincarem e pensarem sobre assuntos diversificados e discutirem sobre suas inquietações e vivências de forma lúdica e concomitantemente democrática. 


\section{Resultados e Discussão}

Ao se pensar acerca da reclusão nos espaços domésticos, nos quais a vida das crianças é também permeada por tais acontecimentos, algumas questões são indicadas e levantadas, tais como a reconfiguração das ações docentes, os campos de estudos e os tempos do aqui e agora. Sendo assim, há uma necessidade de ampliar discussões sobre a atuação dos projetos de extensão que ocorrem juntamente à comunidade. Diante dessa perspectiva, é importante pensar a questão: o que é o Ensino Remoto de Emergência (ERT)?

Em busca de responder a essa questão, tem-se definição de que:

[...] o Ensino Remoto de Emergência (ERT) é uma mudança temporária para um modo de ensino alternativo devido a circunstâncias de crise. Envolve o uso de soluções de ensino totalmente remotas para o ensino que, de outra forma, seriam ministradas presencialmente ou como cursos híbridos, e, que retornarão a esses formatos assim que a crise ou emergência diminuir ou acabar. O objetivo nessas circunstâncias não é recriar um sistema educacional robusto, mas fornecer acesso temporário a suportes e conteúdos educacionais de maneira rápida, fácil de configurar e confiável, durante uma emergência ou crise (Hodges, Trust, Moore, Bond \& Lockee 2020, p. 06).

Em virtude da emergência, a utilização da ERT é uma maneira de manter o vínculo das crianças, adolescentes e jovens com a possibilidade de acesso à educação em tempos de pandemia e de isolamento social.

A utilização da ERT tem como um dos indicativos que a elaboração e o encaminhamento de ações de ensino e aprendizagem necessita de atividades lúdicas que possam ser feitas no ambiente doméstico e sob a supervisão dos pais ou responsáveis. Tais atividades são essenciais para a efetivação e realização das ações propostas no projeto de extensão, cujos princípios pedagógicos foram fundamentados na Educação Social em Saúde.

A Educação Social em Saúde pode ser compreendida como uma área de estudos da educação que contempla o atendimento educacional de crianças, adolescentes, jovens e idosos que estejam vivenciando tratamento de saúde, temporário ou não, visando à promoção da autonomia do sujeito, considerando-o como protagonista de sua história e, a partir disso, realizar a leitura de mundo de modo crítico e reflexivo, tendo em vista transformar a realidade.

Os estudos e as práticas da Educação Social em Saúde estão fundamentados nos pressupostos teóricos e metodológicos da pedagogia de Paulo Freire, que defende a "pedagogia fundada na ética, no respeito à dignidade e a própria autonomia do educando" (Freire, 2002, p. 7).

Conforme expõem Schütz e Luckmann (1973, P. 10), “[...] quanto mais nos alejamos de realidade intersubjetiva, tanto mas atrás dejamos el mundo de la vida cotidiana, que nos es um mundo privado, sino el de nuestra experiencia comum". Pois o mundo da vida é o fundamento inquestionável da concepção natural de mundo, na qual o homem pode intervir e pode adentrar múltiplas relações sociais.

Nas atividades pedagógicas realizadas no ambiente on-line, as brincadeiras conduzidas apresentavam em seu conteúdo elementos para o desenvolvimento das funções psicológicas superiores, uma vez que envolviam conceitos de objetos (cores, formas, tamanho), memória, atenção, linguagem oral e escrita, linguagem matemática. De acordo com Vygotsky, Luria e Leontiev (1998), as funções psicológicas superiores do ser humano desenvolvem-se por meio das interações humanas mediadas por signos e instrumentos.

Ao propormos a brincadeira elefantinho colorido, além de trabalharmos as cores, foi possibilitado à criança trabalhar a memória, uma vez que elas não poderiam repetir as cores já enunciadas pelos outros participantes. Por meio dessa brincadeira, evidenciamos que a criança e o adolescente, ao escolherem o objeto que continha a cor pronunciada, buscavam trazer objetos que demonstrassem o que eles mais gostavam como por exemplo a roupa favorita, um bichinho de pelúcia, dentre outros.

Isso demonstra que ao se utilizar a brincadeira como estratégia de intervenção, pode-se afastar a concepção de que ao brincar, a criança apenas realiza alguma atividade em seu tempo livre. Na concepção teórica do psicólogo russo Vygotsky 
(1988), a brincadeira é um dos elementos que integra o processo de desenvolvimento humano, que é mediado socialmente, no qual a interação social e a construção de significado influenciam no desenvolvimento cognitivo, social cultural e emocional, propiciando a interação entre aprendizado e desenvolvimento.

De acordo com Cotonhoto, Rossetti e Missawa (2019, p. 4):

Na perspectiva de Vygotsky o brincar pode ser definido como uma maneira de interpretar e assimilar o mundo. As crianças, durante os jogos e brincadeiras, estabelecem relações e representações, o que desencadeia o desenvolvimento de capacidades sociais, cognitivas e afetivas na medida em que elas "extrapolam" seu mundo habitual. Ao brincarem, as crianças planejam, criam hipóteses, desenvolvem a imaginação, constroem relações, tomam decisões e elaboram regras de convivência.

Assim posto, ao ser pensar em crianças que estão passando por tratamento de saúde, o Brasil possui legislações específicas que buscam garantir o direito a estes, como o direito de brincar, ao lúdico e à cultura. Dentre várias legislações que procuram assegurar tais direitos, temos a Constituição Federal de 1988 (Brasil. 1988), o Estatuto da Criança e do Adolescente (Brasil, 1990) e a Lei 11.104 de 2005 (Brasil, 2005), que trata sobre a obrigatoriedade de brinquedotecas nas unidades de saúde que ofertam atendimento pediátrico em regime de internação. Temos que no ano de 2018 foi adicionada à lei de Diretrizes e Bases da Educação-Lei 9.394 de 1996 (Brasil, 1996) a Lei 13.716 de 2018 (Brasil), que garante o direito de educação para crianças e adolescentes. Em seu artigo 4, temos que:

Art. $4^{\circ}$-A. É assegurado atendimento educacional, durante o período de internação, ao aluno da educação básica internado para tratamento de saúde em regime hospitalar ou domiciliar por tempo prolongado, conforme dispuser o Poder Público em regulamento, na esfera de sua competência federativa (Brasil. 1996, p. 3).

Mesmo existindo essas legislações, ainda há muito que se discutir sobre essa questão, estamos caminhando, precisamos avançar na garantia dos direitos, pois as crianças e adolescentes que estão em tratamento de saúde acabam se tornando excluídos por não poderem frequentar as aulas e não vivenciarem as suas infâncias de forma plena. Atualmente, poucos hospitais e locais de atendimento no Brasil possuem brinquedotecas e professores que asseguram a educação, dessa forma, esses direitos são negados em várias instituições. Paula contribui ao afirmar que:

No que se refere à Pedagogia Hospitalar, durante muitos anos, as crianças e adolescentes hospitalizados foram marginalizados pelo sistema educacional. Por estarem internados, eles foram considerados incapazes de dar prosseguimento a seus estudos. Essas concepções fizeram com que muitas crianças e adolescentes tivessem uma dupla exclusão social, pois além de serem penalizados por suas doenças, também não tinham acesso à educação (Paula, 2020, p. 2).

Diante do que foi exposto, o lúdico, a arte, a brincadeira, a literatura são meios de permitir que essas crianças, mediante situação de vulnerabilidade, permaneçam inseridas em ambientes que possibilitem seu desenvolvimento cognitivo, social e cultural. Sabe-se que a brincadeira não deve ser considerada um mero passatempo, pois possibilita que a criança crie relações com seus pares e passe a compreender a si mesma e ao mundo.

O brincar de faz-de-conta, por sua vez, possibilita que as crianças reflitam sobre o mundo. Ao brincar, as crianças podem reconstruir elementos do mundo que as cerca com novos significados, tecer novas relações, desvincular-se dos significados, tecer novas relações, desvincular-se dos significados imediatamente perceptíveis e materiais para atribuir-lhes novas significações, imprimir-lhes suas ideias e os conhecimentos que têm sobre si mesma, sobre as outras pessoas, sobre o mundo adulto, sobre lugares distantes e/ou conhecidos (Brasil, 1998, p. 171). 
Ao brincar, a criança procura representar sua relação com o outro, muitas vezes aquele com quem possui maior interação. Ao reproduzir essas ações a criança começa a ter a capacidade de se colocar no lugar do outro, passa a ter autonomia, dando voz aos seus desejos e inquietações durante a brincadeira. Nesse sentido, Navarro (2009) afirma que "Brincar é preciso, é por meio dele que as crianças descobrem o mundo, se comunicam e se inserem em um contexto social". Tais questões não são diferentes para as crianças e adolescentes que se encontram em tratamento de saúde, temos que:

Quando as pessoas brincam, elas desenvolvem o equilíbrio e reciclam suas emoções vividas, além de motivar outros elementos como a atenção, a concentração e muitas outras habilidades, uma vez que mergulham em um mundo de possibilidades. Assim esse é um momento de recriar e enfrentar situações por elas vividas no dia a dia, por isso o brincar para pessoas em tratamento de saúde não pode ser vazio, precisa ser planejado e por vezes repensado para que a saúde física e emocional dessas pessoas seja preservada (Paula, Silva, Silva, \& Santos 2016, p. 451).

Quando se pensa no brincar para crianças em tratamento de saúde, não se pode desconsiderar os indivíduos que fazem parte da sua realidade, sendo em sua maioria os familiares, que são os mais próximos e estão presentes no tratamento e nas atividades do cotidiano, como as atividades escolares e a participação em projetos destinados a eles. Bonetti (2007, p. 3) corrobora ao defender que o lugar ideal para a criança é junto ao seus pais ou familiares, sendo nesse âmbito que encontrará apoio e aconchego para a formação de valores, delineando sua personalidade e o seu caráter. Compreendemos que uma família pode ter várias configurações que irão além da herança genética e do meio familiar composto pelo casamento.

Dessa forma, temos que as relações afetivas são fundamentais para as crianças e adolescentes que estão passando por tratamento de saúde. Sendo assim, por meio da brincadeira, crianças e adolescentes vão estabelecendo essas relações e passando a compreender o mundo de uma outra maneira, passando a construir sua própria identidade e a se autoconhecerem.

E brincando que a criança constrói sua identidade, conquista sua autonomia, aprende a enfrentar medos e descobre suas limitações, expressa seus sentimentos e melhora seu convívio com os demais, aprende entender e agir no mundo em que vive com situações do brincar relacionadas ao seu cotidiano, compreende a aprender a respeitar regras, limites e os papéis de cada um na vida real; há a possibilidade de imaginar, criar, agir e interagir, auxiliando no atendimento da realidade (Modesto \& Rubio, 2014, p. 3).

Com base nas ideias de Modesto e Rubio (2014), entende-se que o brincar é primordial para o desenvolvimento, pois, por meio da brincadeira e do faz-de-conta, a criança cria oportunidades e passa a refletir e compreender sobre seus direitos. Assim, Lopes e Paula (2012) corroboram com essa discussão ao apresentarem que:

Através do brincar a criança expressa sua visão de si e do mundo no qual vive, reproduz e recria comportamentos culturais. Ao brincar, o foco não está mais na doença e no tratamento, mas no lúdico e em todo o universo de possibilidades que a ação de brincar convida a criança a participar e compartilhar estas ações com amigos (Lopes \& Paula, 2012, p. 170).

Quando mesmo em tratamento de saúde, é permitido às crianças brincarem, estas passam a compreender que ainda que se encontrem em um estado de vulnerabilidade, possuem direitos. Assim, é fundamental que pensem sobre seus corpos, suas especificidades, suas vivências, sobre os tratamentos, bem como acerca do direito de brincar, à educação e, fundamentalmente, o direito de ser respeitado, tendo como base as inquietações postas por elas e seus familiares.

Paula e Foltran (2007) relatam como é importante a brincadeira para essas crianças que estão passando por tratamento de saúde, pois, segundo as autoras:

Quando uma criança ou um adolescente hospitalizado brinca ou consegue ter momentos de distração e de divertimento no contexto hospitalar, mergulham em um universo de possibilidades, pois nestes espaços eles recriam e 
enfrentam situações vividas por eles no seu cotidiano. E por isso que crianças e adolescentes precisam usufruir dos benefícios emocionais, intelectuais e culturais que as atividades lúdicas proporcionam (Paula \& Foltran, 2007, p. 3).

É por meio da brincadeira e do diálogo que a criança começa a expressar seus sentimentos, suas alegrias, sonhos e angústias, ao se relacionarem com o outro, vão criando laços de afetividade, o que contribui para seu desenvolvimento e aprendizado.

As relações afetivas para as crianças e adolescentes que se encontram em tratamento de saúde são essenciais, pois possibilitam que os indivíduos expressem suas alegrias, seus medos, suas dores, passem a respeitar o tempo e espaço do outro e a compreender o próximo. Dessa forma, começam também a se reconhecer como indivíduos que, mesmo passando por um tratamento de saúde, possuem deveres e direitos que devem ser respeitados.

Dessa forma, fica evidente que a brincadeira e a afetividade formam um par inseparável o qual permite que as crianças vivenciem novas experiências, novas relações e novas conquistas que potencialmente possibilitam diferentes aprendizagens. "Pequenos gestos como sorrir, escutar, refletir, respeitar são, entre tantos outros, necessidades que levam o sujeito a investir na afetividade, que é o "combustível” necessário para a adaptação, a segurança, o conhecimento e o desenvolvimento da criança" (Mello \& Rubio, 2013, p. 7).

Durante as atividades lúdicas propostas no projeto de extensão, foi possível possibilitar que as crianças pudessem narrar suas experiências em relação à pandemia e ao fato de permanecerem em casa sem poderem estabelecer contato com os colegas, com o professor ou o ambiente escolar. Tal experiência remete às questões da antropologia da infância, cujo foco epistemológico é a relação com o outro, evocada a partir dos contextos social e cultural nos quais o indivíduo está imerso.

Do ponto de vista antropológico, a criança é compreendida como sujeito social e, como tal, é preciso compreendê-la em seu contexto sociocultural e criar possibilidades para que expressem seus pensamentos e sentimentos em relação ao mundo no qual estão inseridas (Cohn, 2005).

Conforme Cohn (2005, p. 35), “[...] as crianças elaboram sentidos para o mundo e suas experiências compartilhando plenamente de uma cultura [...] os sentidos que elaboram parte de um sistema simbólico compartilhado com os adultos".

Nesse momento, as crianças em tratamento de câncer, assim como milhares de outras crianças ao redor do mundo e no Brasil, estão vivenciando a pandemia. Dentro desse contexto, os recentes estudos que aportam no mundo acadêmico-científico abordando a pluralidade das infâncias e das crianças (Pastore, 2020), o funcionamento e desenvolvimento psicológico das crianças (Linhares e Enumo, 2020) e o estabelecimento de rotinas para crianças (Oliveira, Gomes, \& Barcellos, 2020) trazem consigo as marcas dos efeitos do isolamento prolongado e do afastamento do espaço escolar, bem como seus impactos no cotidiano das crianças, pois atualmente "o playground não é o lugar para brincar" (Guizzo, Marcello \& Muller, 2020) e nem no pátio da escola na hora do recreio.

Durante as brincadeiras, buscamos sempre apresentar os diretos da criança e do adolescente por meio de conversas, o que era um dos nossos objetivos. Mostrar a eles que mesmo passando por tratamento de saúde, têm direitos que devem ser respeitados, sendo assim, ao optarmos pelas rodas de conversa entre uma brincadeira e outra, procurávamos observar os gestos e a entoação da voz de cada indivíduo.

No último encontro, pedimos que os participantes falassem sobre alguns direitos e deveres da criança e do adolescente, uma das participantes disse que "é direito dela comer, é direito dela dormir, cantar. Dever é fazer tarefa, arrumar a cama. Gente, não sei vocês, mas acho que é direito da criança assistir também”. Já para outra criança, é direito da criança ter parquinho (Diário De Campo, 30 de novembro de 2020).

Durante as falas, percebemos a importância dessas crianças e desses adolescentes neste projeto de extensão. Eles puderam realizar ações novas em seu cotidiano por meio das brincadeiras, dialogar sobre temas diversificados, como diferença, direito à educação, assim tendo seu direito de brincar nessa época de distanciamento social garantido. 


\section{Considerações Finais}

A Educação Social em Saúde é um campo de práticas e de conhecimento que tem se ocupado diretamente da criação de vínculos entre a ação e o pensar e o fazer cotidiano de indivíduos que estão em tratamento da saúde e que precisam que seus direitos de acesso à educação sejam assegurados em todos os espaços. Nesse sentido, o projeto de extensão tem contribuído para a integração e promoção do desenvolvimento de crianças que participam do projeto, bem como para a formação inicial dos estudantes de Pedagogia participantes e os estudantes de pós-graduação.

Com a realização deste estudo, pode-se constatar que a brincadeira é fundamental para o processo do desenvolvimento, porém, é preciso saber como utilizar o brincar para que de fato ocorra o desenvolvimento. Não é a todo momento que eles desejarão brincar, há momentos nos quais estarão indispostos devido ao tratamento, enquanto em outros não se sentirão à vontade por medo de se exporem. Assim, é preciso respeitar o espaço e o tempo da criança e do adolescente, de forma a contribuir para o seu bem-estar e não causar nenhum tipo de constrangimento.

Dessa forma, temos que além de possibilitar novas relações, o brincar é considerado uma forma criativa de proporcionar às crianças novas formas de conhecimentos e possibilitar o seu desenvolvimento integral.

No âmbito deste projeto, o contato com as crianças por meio da ferramenta Google Meet trouxe aos educadores/pesquisadores envolvidos o conhecimento da realidade que as crianças estão vivenciando durante a pandemia. Conhecer tal realidade se tornou o elemento fundante da prática pedagógica, pois contribuiu para conhecer a vida cotidiana e, assim, a necessidade das atividades lúdicas em ambiente on-line para a sociedade, em particular neste período de distanciamento social da pandemia em decorrência do COVID-19.

Finalizamos este trabalho, mas iniciamos novos caminhos, diante dos diálogos com as crianças e familiares nos sentimos motivados a continuar as ações no projeto de extensão e de discutirmos sobre os direitos das crianças com os pais ou responsáveis, uma das sugestões é a realização de encontros com os familiares, levando a eles informações sobre o direito das crianças e adolescentes que se encontram em tratamento de saúde.

\section{Agradecimentos}

O presente trabalho foi realizado com apoio da Coordenação de Aperfeiçoamento de Pessoal de Nível Superior Brasil (CAPES).

\section{Referências}

Almarzook, Z. I., \& et al. (2020). Uma Tecnologia Disruptiva na Pós-Graduação em Educação Médica: aprendizado virtual durante a pandemia covid-19. J Am Coll Cardiol. 75(20), 2635-2638.

Bezerra, C (2018). Ser diferente é legal. Fontelene Publicações.

Bogdan, R. C.; Biklen, S. K (1994). Investigação qualitativa em educação: uma introdução à teoria e aos métodos. Porto Editora.

Bonetti, S. T. (2007). A interferência da família na aprendizagem matemática das crianças. O professor PDE e os desafios da escola pública paranaense, 2007. Curitiba. SEED/PR, 2007, V. 1. (Cadernos PDE).

Brasil (1988). Constituição (1988). Constituição da República Federativa do Brasil. Supremo Tribunal Federal.

Brasil. (1996) Lei das Diretrizes e Bases da Educação.

Brasil (1998) Referencial curricular nacional para educação infantil: conhecimentos do mundo.

Brasil (2005) Lei no 11.104 de 21 de março de 2005. Dispõe sobre a obrigatoriedade de instalação de brinquedotecas nas unidades de saúde que ofereçam atendimento pediátrico em regime de internação. Diário Oficial [da] República Federativa do Brasil, DF.

Brasil (2018). Lei no 13.716, de 24 de setembro de 2018. http://www.planalto.gov.br/ccivil_03/Constituicao/Emendas/Emc/emc59.htm

Brasil (1990). Lei no 8.069, de 13 de julho de1990. Dispõe sobre o Estatuto da Criança e do Adolescente e dá outras providências. Diário Oficial [da] República Federativa do Brasil, DF. 
Cohn, C. (2005). Antropologia da criança. Zahar.

Cotonhoto, L. A., Rossetti, C., \& Missawa, D. D. A. (2019). A importância do jogo e da brincadeira na prática pedagógica. Constr. Psicopedag. 27(28), 37-47. http://pepsic.bvsalud.org/scielo.php?script=sci_arttext\&pid=S1415-69542019000100005

Freire, P. (1967). Educação como prática de liberdade. Paz e Terra.

Freire, P. (1989). Educadores de rua: uma abordagem crítica-alternativas ao atendimento de meninos e meninas de rua. Bogotá: Nueva.

Freire, P. (2002). A pedagogia da autonomia. Paz e Terra.

Gazzinelli, M. F., Gazzinelli, A., Reis, D. C., \& Penna, C. M. M. (2005). Educação em Saúde: conhecimentos, representações sociais e experiências com doenças. In: Cadernos de Saúde Pública, Rio de Janeiro, 21(1):200-206.

Guizzo, B. S., Marcello, F. de A., \& Muller, F. (2020). A reinvenção do cotidiano em tempos de pandemia. In: Educação e Pesquisa. São Paulo, 46(1), e238077.

Hodges, C., Trust, C., Moore, S., Bond, A \& Lockee, B. (2020). Diferenças entre o aprendizado online e o ensino remoto de emergência. Revista da Escola, Professor, Educação e Tecnologia. 2(1) 2020 escribo.com/revista.

Iacocca, L. (2015). A girafa sem sono. (6a ed), Ática.

Linhares, M. B. M., \& Enumo, S. R. F (2020). Reflexões baseadas na Psicologia sobre efeitos da pandemia COVID-19 no desenvolvimento infantil. Estudos de psicologia (Campinas), 37(1). https://doi.org/10.1590/1982-0275202037e200089

Lopes, B. A., \& Paula, E. M. A. T. (2012). O significado das festas em uma brinquedoteca hospitalar: promoção da saúde, da cultura e da vivência da infância para crianças enfermas. Sociedade Brasileira de Psicologia Hospitalar. 15(1).

Mafra, A. H. (2015). Metodologias de pesquisa com crianças: desafios e perspectivas. Revista zero a seis. 17(31), 107-119.

Mello. T., \& Rubio. J. A. S. (2013). A importância da afetividade na relação professor/aluno no processo de ensino/aprendizagem na educação infantil. Revista Saberes da Educação, 4(1), 1-11.

Modesto, C. M., \& Rubio, J. A. S. (2014). A importância da Ludicidade na Construção do Conhecimento. Saberes da Educação, 5(1), 1-16.

Navarro, M. S. (2009). O brincar na educação infantil. In: IX Congresso nacional de educação; III Encontro sul brasileiro de psicopedagogia, Curitiba, Paraná (pp. 2213-2137).

Oliveira, J. B. A., Gomes, M., \& Barcellos, T. (2020). A covid-19 e a volta às aulas: ouvindo as evidências. Ensaio: aval.pol. públ. EDUC., 28(108), 555-578.

Paula, E. M. A. T., Foltran, E. P. Brinquedoteca hospitalar: Direito das crianças e adolescentes hospitalizados. Revista Conexão UEPG, 3(1), 1-5.

Paula, E. M. A. T., Silva, M. O., Silva, L. T., \& Santos, M. A. (2016). As concepções de acadêmicos sobre práticas lúdicas em um projeto de extensão em hemocentro. Revista Conexão UEPG. 12(3) set/dez.

Pastore, M. D. Infâncias, crianças e pandemias: em que barco navegamos? Cadernos brasileiros de terapia ocupacional. Brazilian Journal of Occupational Therapy, Preprint, 2020.

Rocha, R. (2014). Os direitos das crianças. Salamanca.

Rodrigues, S. A., Borges, T. F. P., \& Silva, A. S. (2014) “Com os olhos de criança”: A metodologia de pesquisa com crianças pequenas no cenário brasileiro. Nuances: estudos sobre educação, Presidente Prudente-SP, 25(2), 270-290.

Terence, A. C., \& Filho, E. E. (2009). Abordagem Quantitativa e qualitativa da pesquisa-ação nos estudos organizacionais. Associação Brasileira de Engenharia da Produção, XXVI ENEGEP, 2009, 1-9.

Vergara, S.C. (2005). Métodos de pesquisa em Administração. Atlas.

Vygotsky, L. S. (1988) A formação social da mente. (2a ed), Martins Fontes

Vygotsky, L. S., Luria, A. R., \& Leontiev, A. N. (1998). Linguagem, desenvolvimento e aprendizagem. Icone.

Yin, R. K. (2001). Estudo de caso: planejamento e método. (2a ed), Bookman. 